\title{
Intraperitoneal Lethal Injection
}

\section{Euthanasia}

National Cancer Institute

\section{Source}

National Cancer Institute. Intraperitoneal Lethal Injection Euthanasia. NCI Thesaurus.

Code C116226.

A method of euthanasia whereby a subject is given a lethal intraperitoneal injection to induce death. 